\title{
Antibiotic susceptibility patterns of bacteria isolates in post-operative wound infections among patients attending Mama Lucy Kibaki Hospital, Kenya
}

Johnstone Amulioto ( $\square$ jamulioto@gmail.com )

Kenyatta University School of Medicine https://orcid.org/0000-0002-2906-3780

Margaret W. Muturi

Kenyatta University School of Medicine

Scholastica Mathenge

Kenyatta University School of Medicine

Gideon M. Mutua

Mama Lucy Kibaki Hospital

Research article

Keywords: Surgical site infection, antibiotic susceptibility, bacteria prevalence, Mama Lucy Kibaki Hospital

Posted Date: November 25th, 2019

DOI: https://doi.org/10.21203/rs.2.17645/v1

License: (9) (1) This work is licensed under a Creative Commons Attribution 4.0 International License. Read Full License 


\section{Abstract}

Background Surgical site infections accounts for high mortality rates, morbidity and elevated costs of treatment for surgical patients. In recent years, surgical site infections attributed to antibiotic resistant bacteria has been on the rise globally. To effectively formulate a comprehensive treatment protocol for surgical site infection, there is need for knowing the likely causative agents and their antibiograms. In this regard, this study sought to determine the prevalence and antibiotic susceptibility patterns of bacteria isolates from post-operative wound infections among patients attending Mama Lucy Kibaki Hospital.

Methods A cross-sectional descriptive study was carried out between October 2018 and March 2019. The study included patients of all age group with surgical site infections following general, obstetrics and gynecological surgeries. Pus swabs were aseptically obtained from 58 consented patients with clinical evidence of surgical site infections. Gram stain, culture, biochemical tests and antibiotic susceptibility tests were done for each pus swab. Antibiotic susceptibility testing was done using Kirby bauer disc diffusion method. Data was analysed using a statistical package for the social sciences (SPSS) version 20.

Results An isolation rate of $94.8 \%$ was observed. Staphylococcus aureus $28.2 \%$ was the preponderant isolate followed by Escherichia coli $15.4 \%$ with Methicillin resistant Staphylococcus aureus accounting for $65.4 \%(n=17)$ of the total Staphylococcus species. Chloramphenicol was the most sensitive drug to all the bacteria isolates. Ampicillin and Amoxycillin recorded resistance rates $>90 \%$ against positive and gram negative bacteria respectively. Klebsiella pneumoniae $81.3 \%$ and E.coli $74 \%$ were the most resistant bacteria.

Conclusion Majority of the drugs were resistant to gram negative rods, therefore there is need for continuous monitoring to determine the susceptibility patterns of the most common surgical site infections bacteria isolates which are found in the hospitals.

\section{Introduction}

Surgical sites infections (SSI) are a worldwide problem in the field of surgery accounting for increased deaths, morbidity and elevated healthcare costs in surgical patients [1][2]. The rates of these infections worldwide vary greatly, with most studies observing incidence rates of between $2.6 \%-58 \%$ [3][4][5]. The implicated pathogens vary from one setting to the other, with several researchers observing Staphylococcus aureus, Pseudomonas aeruginosa (39.13\%), Escherichia coli and Klebsiella pneumoniae (25.5\%) as the predominant SSI bacteria isolates [6][7][8][9].

An increasing proportion of these infections are due to multi-drug resistant bacteria and this has complicated the treatment of SSIs [10]. This resistance has been attributed to the irrational use of antimicrobial agents which has exerted selective pressure on bacteria leading to the emergence of resistant bacterial strains [11]. Moreover, the decline in antibiotic development pipeline has further complicated the treatment of SSIs [12]. Successful treatment of these infections depends on accurate 
identification of etiologic agents and their antibiogram profiles. However, there is a paucity of clinical microbiological data especially in developing countries which has hampered the management of these infections [13].

In Kenya, the situation is the same with regard to the paucity of this data. Hence, this study was done to determine the prevalence and antibiotic susceptibility profiles of bacteria isolates in post-operative wound infections among patients attending Mama Lucy Kibaki Hospital. The results are intended to help clinicians when formulating a comprehensive treatment protocol for SSIs. Pre-operative surgical prophylaxis also rely on local susceptibility profiles of bacteria.

\section{Methods}

\section{Study design and setting}

This was a cross-sectional descriptive study carried out at Mama Lucy Kibaki Hospital for a period of 6 months, between October 2018 and March 2019. Mama Lucy Kibaki Hospital is a level 5 public health facility located in the eastern part of Nairobi city, Kenya. This study included patients of all age group with surgical site infections following general, obstetrics and gynecological surgeries. The patients were drawn from the surgical wards, maternity wards and pediatric ward. Those patients who did not consent were excluded.

\section{Sampling}

Patients with surgical site infection were identified by surgeons during routine ward rounds and the clinical information documented in patient file. The same information was relayed to the principal investigator through the clinicians. Eligible patients were taken through the research process and informed consents obtained. A serialized structured questionnaire was used to collect additional patient clinical data.

\section{Sample collection}

The pus swabs were aseptically obtained from 58 patients with clinical evidence of surgical site infection (drainage from incision) within the research period. After the wound immediate surface exudates and contaminants were cleansed off with sterile moistened gauze and normal saline solution. The pus was collected using a moistened sterile cotton swab from the deep viable tissues of the wound by Levine method [14]. The collected swab was then placed in a tube with Stuart transport medium and the replaced cap tightened. Two pus swabs were collected from each patient, one for gram stain and the 
other for culture. All the swabs were carefully labelled and transported immediately to Kenyatta university laboratory in appropriate leak proof specimen transport bags.

\section{Bacterial culture and identification}

Upon reaching the laboratory, all the pus swabs were carefully checked and their details entered into the investigators booklet. Smears of the pus swabs were prepared, gram stained and examined microscopically. The other swabs from each patient were inoculated on MacConkey agar and blood agar and the inoculated plates incubated at $35-37^{\circ} \mathrm{C}$ for 24 hours. After incubation, the plates were examined for growth. Colony characteristics such as swarming growth and hemolysis on blood agar, changes in physical appearance in differential media and enzymatic activities of the organisms were used for preliminary bacterial identification. Biochemical tests such as catalase, coagulase, urease, indole, methyl red, voges proskauer and citrate (IMViC) tests were performed for the identification of the various bacteria.

\section{Antibiotic susceptibility testing}

Antibiotic susceptibility testing was performed on Mueller Hinton agar using various antibiotics by Kirby bauer disc diffusion method as per standards prescribed in bacteriology [15]. Using a sterile swab, Mueller Hinton agar surface was uniformly coated with the suspension of the test organism matching 0.5 McFarland turbidity standard. Following incubation of test plates and controls at $35^{\circ} \mathrm{C}$ for 24 hours, the plates were examined for confluent growth. Escherichia coli ATCC 25922 and Staphylococcus aureus ATCC 25923 were used as control strains. The zones of inhibitions were determined using breakpoints provided by Clinical and Laboratory Standards Institute and British society for antimicrobial chemotherapy [16][17]. The following antibiotics were tested; Chloramphenicol (50ug), Vancomycin (30ug), Amoxycillin (30ug), Doxycycline (30ug), Ciprofloxacin (30ug), Cefepime (30ug), Ceftriaxone (30ug), Amikacin (30ug), Gentamicin (30ug), Oxacillin (1 ug), Cotrimoxazole (25ug), Azithromycin (15ug) and Ampicillin (10ug). These antibiotics were selected based on the availability and prescription frequency of these drugs in the study area.

\section{Data analysis}

Data was entered in excel, cleaned and the information exported to IBM statistical package for the social sciences version 20. Descriptive statistics such as mean and percentages were determined. Pearson chisquare test was used to establish the association of social demographic data and the different bacteria isolates. $P$ value of $<0.05$ was considered to indicate statistically significant differences. Finally, the results were presented using tables. 


\section{Results}

A total of 58 cases of surgical site infection were observed at the facility between October 2018 and March 2019. Of these 19 (32.8\%) were males while 39 (67.2\%) were females with pediatric patients accounting for $3(5.2 \%)$ of the total cases. The patients' mean age was 31.12 years, with the youngest and eldest patient being 7 and 61 years respectively.

A total of 78 bacteria were isolated from the culture positive swabs, with monomicrobial and polymicrobial growth occurring in $60.3 \%(35 / 58)$ and $34.5 \%(20 / 58)$ of the swabs respectively. Whereas only $5.2 \%(3 / 58)$ of the swabs were culture negative. Staphylococcus aureus $28.2 \%(n=22)$ was the prevalent isolate followed by E.coli 15.4\% ( $(n=12)$, Acinetobacter species $14.1 \%$ ( $n=11)$, Pseudomonas aeruginosa 9.0\% (n=7), Enterobacter species 9.0\% ( $(n=7)$, Bacillus species $9.0 \%(n=7)$, Coagulase negative staphylococci $5.1 \%(n=4)$, Proteus species $5.1 \%(n=4)$, Klebsiella pneumoniae $2.6 \%(n=2)$, Morganella morganii 1.3\% ( $n=1)$ and Citrobacter freundii $1.3 \%(n=1)$ ( see additional file 1).

Most of the bacteria were recovered from the abdomen $60.3 \%$ and the lower limbs $29.5 \%$, with the arms and other body sites accounting for $3.8 \%$ and $6.4 \%$ of the total bacteria respectively (Table 1). Majority of these isolates were gram negative rods $57.7 \%$ (45) with gram positive bacteria accounting for $42.3 \%$ (33) of the total bacteria. This number was high in female patients $73.1 \%$ (57) than male patients $26.9 \%(21)$ but the difference was not statistically significant $(p=0.136)$. Chloramphenicol $90.9 \%(n=30 / 33)$, Vancomycin $87.9 \%(n=29 / 33)$ and Doxycycline 75.8\% $(n=25 / 33)$ were highly sensitive to gram positive bacteria. However Azithromycin 36.4\% ( $n=12 / 33)$ and Ampicillin (3.0\%) $(n=1 / 33)$ had the lowest sensitivity rates for gram positive bacteria (Table 2 ).

Cefepime, Gentamicin and Amikacin showed $100 \%$ resistance to Acinetobacter species and Klebsiella pneumoniae respectively. Chloramphenicol $53.3 \%(n=24 / 45)$ was the only drug that had the highest sensitivity for gram negative rods. Multi-drug resistance (resistance to $\geq 4$ antibiotics) was observed with Klebsiella pneumoniae and E.coli (Table 3). Among gram positive bacteria, Methicillin resistant Staphylococcus aureus (MRSA) accounted for $65.4 \%(n=17 / 26)$ of the total Staphylococcus species (Table 2).

Table 1 Proportions of bacteria isolated from different wound sites 
Wound site $\quad$ Types and proportions of bacteria isolates

Gram positive bacteria N (\%) Gram negative bacteria N (\%) Total isolates

$N(\%)$

\begin{tabular}{llll} 
Abdomen & $24(51.1)$ & $23(48.9)$ & $47(60.3)$ \\
\hline Lower limbs & $7(30.4)$ & $16(69.6)$ & $23(29.5)$ \\
\hline Arms & $1(33.3)$ & $2(66.7)$ & $3(3.8)$ \\
\hline $\begin{array}{l}\text { Other body } \\
\text { regions }\end{array}$ & $1(20.0)$ & $4(80.0)$ & $5(6.4)$ \\
\hline
\end{tabular}

Table 2 Antibiotic susceptibility pattern of gram positive bacteria

Types of bacteria isolates

Tested antibiotics

\begin{tabular}{|c|c|c|c|c|c|c|c|c|}
\hline & & VA & CIP & $\mathrm{C}$ & DO & $A X$ & AZM & ox \\
\hline & & $\begin{array}{l}\text { 30ug } \\
(\%)\end{array}$ & (\%) & $\begin{array}{l}\text { 50ug } \\
\text { (\%) }\end{array}$ & $\begin{array}{l}\text { 30ug } \\
(\%)\end{array}$ & $\begin{array}{l}\text { 10ug } \\
(\%)\end{array}$ & $\begin{array}{l}\text { 15ug } \\
\text { (\%) }\end{array}$ & $\begin{array}{l}\text { 1ug } \\
(\%)\end{array}$ \\
\hline \multirow[t]{3}{*}{ Staphylococcus aureus } & $S$ & 90.9 & 77.3 & 95.5 & 86.4 & 4.5 & 50.0 & 27.3 \\
\hline & I & 0.0 & 9.1 & 0.0 & 9.1 & 0.0 & 4.5 & 13.6 \\
\hline & $\mathrm{R}$ & 9.1 & 13.6 & 4.5 & 4.5 & 95.5 & 45.5 & 59.1 \\
\hline \multirow{3}{*}{$\begin{array}{l}\text { Coagulase negative } \\
\text { staphylococci }\end{array}$} & $S$ & 75.0 & 100.0 & 100.0 & 50.0 & 0.0 & 25.0 & 0.0 \\
\hline & I & 25.0 & 0.0 & 0.0 & 25.0 & 0.0 & 0.0 & 0.0 \\
\hline & $\mathrm{R}$ & 0.0 & 0.0 & 0.0 & 25.0 & 100.0 & 75.0 & 100.0 \\
\hline \multirow[t]{3}{*}{ Bacillus species } & $S$ & 85.7 & 28.6 & 71.4 & 57.1 & 0.0 & 0.0 & - \\
\hline & I & 0.0 & 42.9 & 14.3 & 14.3 & 0.0 & 14.3 & - \\
\hline & $\mathrm{R}$ & 14.3 & 28.6 & 14.3 & 28.6 & 100.0 & 85.7 & - \\
\hline
\end{tabular}

$V A=$ vancomycin, $C I P=$ ciprofloxacin, $C=$ chloramphenicol, $D O=$ doxycycline, $A X=a m p i c i l l i n$, $A Z M=$ azithromycin, $O X=0 x a c i l l i n, S=$ sensitive, I=intermediately sensitive, $R=$ resistant 
Table 3 Antibiotic susceptibility pattern of gram negative bacteria

Types of

bacteria

isolates
Tested antibiotics

$\begin{array}{lllllllll}\text { C } & \text { CIP } & \text { DO } & \text { GEN } & \text { COT } & \text { AMX } & \text { CPM } & \text { AK } & \text { CTR } \\ \text { 50ug } & \text { 30ug } & \text { 30ug } & \text { 10ug } & \text { 25ug } & \text { 30ug } & \text { 30ug } & \text { 30ug } & \text { 30ug } \\ (\%) & (\%) & (\%) & (\%) & (\%) & (\%) & (\%) & (\%) & (\%)\end{array}$

(\%)

Morganella

morganii

0.0

0.0

$100.0 \quad 0.0$

0.0
S 100.0

I 0.0

R 0.0

0.0

Proteus species

$\mathrm{S}$

$\begin{array}{lll}0.0 & 100.0 & 0.0\end{array}$

0.0

0.0

0.0

0.0

$100.0 \quad 0.0$

100.0

100.0

50.0

50.0

0.0

100.

50.

$\begin{array}{lllllll}\mathrm{I} & 50.0 & 50.0 & 0.0 & 0.0 & 0.0 & 0.0 \\ \mathrm{R} & 0.0 & 0.0 & 100.0 & 0.0 & 50.0 & 100.0\end{array}$

Klebsiella

pneumoniae

S

S 50.0

0.0

0.0

0.0

I 0.0

R 50.0

E.coli

S

$S \quad 41.7 \quad 25.0$

I 0.0

R 58.3

$\begin{array}{ll}16.7 & 0.0\end{array}$

$50.0 \quad 50.0$

0.0

$0.0 \quad 0.0$

Pseudomonas
aeruginosa

$\mathrm{S}$

$\begin{array}{lllll}\text { I } & 14.3 & 0.0 & 0.0 & 0.0\end{array}$

$\begin{array}{lllll}\mathrm{R} & 28.6 & 28.6 & 71.4 & 42.9\end{array}$

0.0

0.0

0.0

$\begin{array}{ll}0.0 & 0.0 \\ 0.0 & 0.0\end{array}$


CPM=Cefepime, AK=Amikacin, CTR=Ceftriaxone, CIP=Ciprofloxacin, COT=Cotrimoxazole $\mathrm{C}=$ Chloramphenicol, DO=Doxycycline, GEN=Gentamicin, AMX=Amoxycillin, $\mathrm{S}=$ Sensitive, I=Intermediately Sensitive, R=Resistant

\section{Discussion}

The present work observed monomicrobial growth in $60.3 \%$ (35/58) of the swabs that were cultured, with polymicrobial and culture negative growth occurring in 34.5\% (20/58) and 5.2\% (3/58) of the swabs respectively. These results were comparable to findings from a study carried out in Nigeria which observed single growth in 48 (75\%) samples, with polymicrobial growth occurring in 16 (25\%) samples [18]. Both of these studies observed a high isolation rate of bacteria, except that in the present work three swabs failed to yield any growth which could be attributed to antibiotic use prior to sample collection.

This project managed to isolate a total of 78 bacteria with Staphylococcus aureus as the preponderant bacteria. These results were in harmony with a similar study conducted at one of the national hospital in the country [19]. This predominance of Staphylococcus aureus observed at the current setting was because this bacteria is a skin flora, therefore its presence in surgical wounds could be as a result of endogenous contamination of the surgical site during patient skin incision. Exogenous sources such as contaminated hospital surfaces or equipments and the hands of healthcare providers could also account for Staphylococcus aureus preponderance [20].

However, findings by this work were inconsistent with studies by Namiduru et al [21], Kokate et al [22] and PatelDisha et al [23] which identified E.coli (32.8\%), Pseudomonas aeruginosa and Klebsiella species as the leading causes of surgical site infection. The difference could be attributed to the invasive nature of the procedures performed by hospitals. This is because, patients undergoing procedures involving the gastro-intestinal tract may be at a risk of developing SSI as a result of endogenous contamination of the surgical site with enteric rods during surgery.

The project also saw the predominance of gram negative bacteria over gram positive bacteria which was analogous with findings from a study by Tuon et al [24]. But these results were incongruous with discoveries by a separate research worker who observed the preponderance of gram positive bacteria over gram negative bacteria [25]. The differences in the types of bacteria isolates can be attributed to the different microbiota present in different hospital environments. In addition, the increase in resistance rates of gram negative rods to antibiotics could account for the high prevalence of gram negative rods at the current setting.

The high resistance rates of Amoxycillin and Ampicillin recorded by the present work were in harmony with observations by another worker [26]. Findings on the resistance rates of gram negative rods were comparable to the results obtained from a study in Ethiopia [27]. Additionally, MRSA rate of $65.4 \%$ observed in the present setting was in harmony with results from a study conducted in Uganda that reported a MRSA rate of $65.9 \%$ [28]. These current occurrences were attributed to lack of effective surveillance programs for SSI etiologies and their antibiograms. One of the limitation was the design of 
this study which could not allow for follow-up of patients which meant that some of the cases were never captured.

\section{Conclusions}

The current work observed that Staphylococcus aureus was the leading cause of post-operative wound infection among patients attending the hospital. High resistance rates were observed among gram negative bacteria, with only chloramphenicol as the most sensitive drug to all the isolates. Therefore, there is need for continuous monitoring to determine the susceptibility patterns of the most common bacteria isolates which are found in the hospitals. The current results are intended to assist clinicians during empirical therapy and also in monitoring bacteria resistance trends across institutions.

\section{Abbreviations}

SSI: surgical site infection; KUERC: Kenyatta University Ethics Review Committee; IBM: International Business Machines Corporation; MRSA: Methicillin resistance Staphylococcus aureus; ATCC: American type culture collection.

\section{Declarations}

\section{Ethical approval and consent to participate}

Ethical approval was given by Kenyatta University Ethics Review Committee (KUERC) reference no PKU/700/1772. Informed consents were obtained by signing of informed consent forms by adults. For participants below 18 years, parents or legal guardians would sign the consent forms on their behalf. All the records pertaining to patients were kept anonymous.

\section{Availability of data and Materials}

The datasets supporting the conclusions of this article are included within the article and its additional file. 


\section{Funding}

No funding

\section{Acknowledgements}

The authors would like to thank the hospital administration for the permission to conduct research at the facility. Our heartfelt thanks also go to the technical staff of the Department of Medical Laboratory Science for their technical support.

\section{Consent for publication}

Not applicable

\section{Competing Interests}

The authors declare that they have no competing interests

\section{Author's contributions}

JA was involved in the conception and study design, acquisition of data, interpretation of data and drafting of the manuscript. MM and SM supervised the project and reviewed the draft. GM helped during acquisition of clinical data at the hospital. All the authors read and approved the final manuscript.

\section{References}

1. Badia JM, Casey AL, Petrosillo N, Hudson PM, Mitchell SA, Crosby C. Impact of surgical site infection on healthcare costs and patient outcomes: a systematic review in six European countries. Journal of Hospital Infection. 2017;96:1-15. doi:10.1016/j.jhin.2017.03.004.

2. Gelhorn HL, Anand SB, Parvizi J, Morrison T, Yu H, Pokrzywinski R, et al. Qualitative interviews to identify burden of illness, impacts and costs associated with surgical site infections. Journal of comparative effectiveness research. 2018;7:357-67. doi:10.2217/cer-2017-0075.

3. Rosenthal VD, Richtmann R, Singh S, Apisarnthanarak A, Kübler A, Viet-Hung N, et al. Surgical Site Infections, International Nosocomial Infection Control Consortium Report, Data Summary of 30 Countries, 2005-2010. Infection control and hospital epidemiology. 2013;34:1-8. doi:10.1086/670626.

4. Apanga S, Adda J, Issahaku M, Amofa J, Mawufemor K, Bugri S. Post Operative Surgical Site Infection in a Surgical Ward of a Tertiary Care Hospital in Northern Ghana. Int J Res Health Sci. 
2014;2:207-12.

5. Kaur K, Oberoi L, Devi P. Bacteriological profile of surgical site infections. International archives of Integrated Medicine. 2017;4:77-83. http://iaimjournal.com/. Accessed 29 Dec 2018.

6. Banashankari GS, Rudresh HK, Harsha, Sreeja S. An Overview Of Surgical Site Infections: An Insight Into The Prevalence, Etiology And Predisposing Factors. International Journal of Medical Science and Clinical Inventions. 2014;1:493-9.

7. Patel HK, Patel P, Nerurkar AB. Antimicrobial susceptibility pattern of organisms causing surgical site infection in a tertiary care hospital , Valsad, South Gujarat. Indian Journal of Microbiology Research. 2019;6:71-7.

8. Nwankwo E, Mofolorunsho C, Akande A. Aetiological agents of surgical site infection in a specialist hospital in Kano, north-western Nigeria. Tanzania Journal of Health Research. 2014;16:289-95.

9. Billoro BB, Nunemo MH, Gelan SE. Evaluation of antimicrobial prophylaxis use and rate of surgical site infection in surgical ward of Wachemo University Nigist Eleni Mohammed Memorial Hospital , Southern Ethiopia: prospective cohort study. BMC Infectious Diseases. 2019;19:298.

10. Manyahi J, Matee MI, Majigo M, Moyo S, Mshana SE, Lyamuya EF. Predominance of multi-drug resistant bacterial pathogens causing surgical site infections in Muhimbili national hospital, Tanzania. BMC Research Notes. 2014;7:500. doi:10.1186/1756-0500-7-500.

11. Oz T, Guvenek A, Yildiz S, Karaboga E, Tamer YT, Mumcuyan N, et al. Strength of selection pressure is an important parameter contributing to the complexity of antibiotic resistance evolution. Molecular biology and evolution. 2014;31:2387-401. doi:10.1093/molbev/msu191.

12. Nicholson P. Improving antibiotic prescribing for surgical prophylaxis - the role of perioperative nurses. Journal of Perioperative Nursing. 2019;32:Article 2. doi:10.26550/2209-1092.105.

13. Allegranzi B, Nejad SB, Combescure C, Graafmans W, Attar H, Donaldson L, et al. Burden of endemic health-care-associated infection in developing countries: systematic review and meta-analysis. The Lancet. 2011;377:228-41. doi:10.1016/S0140-6736(10)61458-4.

14. Cooper R. Ten top tips for taking a wound swab. Wounds International. 2010;1:19-20.

15. Hudzicki J. Kirby-Bauer Disk Diffusion Susceptibility Test Protocol. American Society for Microbiology. 2016; December 2009:1-23. https://www.asm.org/Protocols/Kirby-Bauer-DiskDiffusion-Susceptibility-Test-Pro. Accessed 3 Nov 2019.

16. CLSI. Performance Standards for Antimicrobial Susceptibility Testing. 26th edition. CLSI supplement M100S. Wayne, PA: Clinical and Laboratory Standards Institute; 2016.

17. Wootton M. BSAC Methods for Antimicrobial Susceptibility Testing. Bsac. 2013;44 May:1-87.

18. Adegoke AA, Mvuyo T, Okoh Al, Steve J. Studies on multiple antibiotic resistant bacterial isolated from surgical site infection. Scientific Research and Essays. 2010;5:3876-81.

19. Okello SO, Kuremu T, R A, E R, Oliver V. Etiology and Antimicrobial Susceptibility of Surgical Site Infections at Moi Teaching and Referral Hospital, Eldoret-Kenya. International Annals of Medicine. 2018;2. doi:https://doi.org/10.24087/IAM.2018.2.4.459. 
20. Gelaw A, Gebre-selassie S, Tiruneh M, Mathios E, Yifru S. Isolation of bacterial pathogens from patients with postoperative surgical site infections and possible sources of infections at the University of Gondar Hospital , Northwest Ethiopia. Journal of Environmental and Occupational Science. 2014;3:103-8.

21. Namıduru M, Karaoğlan I, Çam R, Boşnak VK, Mete AÖ. Preliminary data of the Surveillance of Surgical Site infections at Gaziantep University Hospital. Journal of Infection and Public Health. 2013;6:289-95. doi:https://doi.org/10.1016/j.jiph.2012.12.008.

22. Kokate SB, Rahangdale V, Katkar VJ. Study of Bacteriological Profile of Post Operative Wound Infections in Surgical Wards in a Tertiary Care Hospital. International Journal of Contemporary Medical Research. 2017;4:232-5. www.ijcmr.com. Accessed 29 Dec 2018.

23. PatelDisha A, PatelKiran B, BhattSeema K, ShahHetal S. Surveillance of hospital acquired infection in surgical wards in tertiary care Centre Ahmedabad, Gujarat. National Journal of Community Medicine. 2011;2:340-5.

24. Tuon F, Cieslinski J, Ono A, Goto F, Machinski J, Mantovani L, et al. Microbiological profile and susceptibility pattern of surgical site infections related to orthopaedic trauma. International Orthopaedics. 2019;43:1309-13.

25. Khyati J, Nilesh SC, S.M J. Bacteriological profile of post-surgical wound infection along with special reference to MRSA in central india , indore. International Journal of Integrative Medical Science. 2014;1:9-13.

26. Kahsay A, Mihret A, Abebe T, Andualem T. Isolation and antimicrobial susceptibility pattern of Staphylococcus aureus in patients with surgical site infection at Debre Markos Referral Hospital, Amhara Region, Ethiopia. Archives of public health. 2014;72:16.

27. Dessie W, Mulugeta G, Fentaw S, Mihret A, Hassen M, Abebe E. Pattern of Bacterial Pathogens and Their Susceptibility Isolated from Surgical Site Infections at Selected Referral Hospitals, Addis Ababa, Ethiopia. International journal of microbiology. 2016;2016:2418902.

28. George M, Iramiot JS, Muhindo R, Olupot-Olupot P, Nanteza A. Bacterial Aetiology and Antibiotic Susceptibility Profile of Post-Operative Sepsis among Surgical Patients in a Tertiary Hospital in Rural Eastern Uganda. Microbiology research journal international. 2018;24:MRJL.41690. doi:10.9734/MRJI/2018/41690. 